\title{
GESTÃO DE ESTOQUES COM INVENTÁRIO FÍSICO: UM ESTUDO DE CASO DE IMPACTOS NA ACURACIDADE DE ESTOQUE DE UMA REDE DE MATERIAL DE CONSTRUÇÃO
}

\author{
Natália Aparecida de Carvalho Mariquito* - FIC/UNIS - nataliamariquito43@gmail.com \\ Natália do Carmo Silva* - FIC/UNIS - nataliacsilva09@gmail.com \\ Mário César Fialho de Oliveira ${ }^{* *}$-FIC/UNIS -mc-mariocesar@hotmail.com \\ Douglas Barbosa**_FIC/UNIS-douglas.barbosa@professor.unis.edu.br \\ Márcia Marazo Pinto** _FIC/UNIS- marcia.marazo@professor.unis.edu.br
}

\section{RESUMO}

A gestão de inventário é uma ação estratégica de grande valia para à gestão de estoque eficaz e valida a confiabilidade das informações contidas. O objetivo deste estudo é aumentar a acuracidade do SKU mais rentável para empresa, analisando o processo AS IS e propondo uma nova modelagem TO BE com uma implantação sem investimento tecnológico de um sistema de inventário rotativo nas operações do processo do estoque de uma Rede de Material de Construção. A modelagem TO BE proposta gerou grandes vantagens no Centro de Distribuição (CD) e com a implementação do inventário rotativo, observou-se a evolução do índice de acuracidade no mês de setembro de 2020, mês da implantação do TO BE, saindo de uma última acuracidade medida no mês de agosto de 2020, depois $96 \%$ na primeira semana do mês de setembro de 2020 e,por fím, alcançando o nível de 98\% de acuracidade na quarta semana. Foram encontradas evidências significativas de relação entre inventário rotativo e acuracidade dos estoques.

Palavras chaves: Acuracidade. Gestão de Inventário.Processo.

\begin{abstract}
Inventory management is a great valuable strategic action for effective inventory management and reliably validates the contained information. The aim of the study is to increase the accuracy of the most profitable SKU for the company, by analyzing the AS IS process and proposing a new SER modeling with an implantation with no technological investment in a rotating inventory system at the operations of the stock process of a building material store chain. The proposed TO BE modeling generated significant advantages in the Distribution Center (DC) and by implementing the rotating inventory, the evolution of the accuracy index in September 2020, month of TO BE implantation, was observed; coming from the last accuracy measured in August 2020, then $96 \%$ in the first week of September 2020 and, finally, reaching the 98\% accuracy level in the fourth week. Evidence of relationship between rotating inventory and stock accuracy were found.
\end{abstract}

Keywords: Accuracy. Inventory Management. Process. 


\section{INTRODUÇÃ̃o}

Com o aumento da competitividade do mercado nos dias atuais, um dos principais motivos para as empresas se inclua em seu processo a gestão de estoques eficiente. Desta forma, os estoques devem ser bem estruturados, executados e monitorados.

Ao âmbito da gestão de estoque, o principal pilar para manter o controle e organização dos produtos é o inventário com sua aplicação no tipo mais assertivo. Mantendo o controle dos materiais armazenados, há garantia e confiabilidade no estoque da empresa e consequentemente, as perdas de materiais são minimizadas. A gestão de inventário implantada na diretriz de melhoria na gestão de estoque se torna extremamente importante para alcance da empresa em ser pioneira no controlee gestão de estoque, pois se há a eficácia do inventário, os estoques físico e virtual se mantêm corretos.

A análise da acuracidade na gestão de estoque ocorreu em uma empresa de materiais de construção na Zona da Mata de Minas Gerais, possuindo sua rede de distribuição de 14 pontos comerciais e 3 Centros de Distribuições (CD). O estudo de casos identificou na organização as oportunidades de melhorias, eficiência no movimento de entrada e saída de estoque, aumento da acuracidade e controle do produto mais rentável para empresa.

Nessa visão, o artigo tem por objetivo melhorar o processo existente de gestão de inventário, visando o aumento da acuracidade do produto considerado o mais prejudicial ocasionando furos no estoque, aumentando a confiabilidade das informações e garantir controle nos produtos do estoque físico e do estoque virtual, propor uma nova modelagem no processo já utilizado sem gastos com tecnologia

A escolha da aplicação do esforço de todo estudo, foi a partir do ranking de produtos mais rentáveis para empresa, assim foi possível realizar a aplicação de forma estratégica. Contudo, a metodologia aplicada pode ser usada em processo futuros sendo que sua aplicação foi de grande valia para o SKU em estudo.

\section{REVISÃO BIBLIOGRÁFICA}

\subsection{Gestão de Estoque}

Segundo Camargo (2017), respeitando as políticas necessárias para armazenagem, a gestão de estoques pode ser considerada como um conjunto de tarefas cuja função é suprir as necessidades da empresa, com agilidade e custo mínimo, por meio da grande movimentação de materiais com capital investido. 
Segundo Rigoleto et al. (2017) a falta de gestão eficiente afeta grande parte das empresas brasileiras, onde frequentemente acontecem a falta de identificação dos movimentos dos seus ativos, além de ter como resultado a perda ou grande alocação de insumos e produtos em estoque. Como forma de buscar a redução desses impactos negativos, é necessária liderança capacitada para que a gestão seja realizada de forma correta com critérios de análise do problema e correção bem definidos, dando base para as tomadas de decisões.

Rodrigues et al (2020) defendem que o gerenciamento do estoque consiste na verificação de ativos da empresa que ficam guardados. Possuir um mapeamento eficiente do estoque é importante, pois assim, se torna capaz o conhecimento do estoque, e aspectos como saber a hora de comprae reposição do estoque, identificar e classificar a matéria contida e armazenada.

(BARBOSA e FILHO, 2019) as empresas utilizam estratégias como adquirir e armazenar produto ou matéria prima, seja para venda ou para a confecção do produto, que são nomeados como estoque.Com a implantação da gestão de estoque e possível planejar suas compras, vendas e demandas, principalmente atuando na obtenção de um estoque enxuto, possuindo somente o índice que for utilizado, sendo assim, denominamos estoque como um ativo de investimento.

\subsection{Gestão de Inventário}

Segundo Rizzotto (2016), dentro das auditorias existem processos que são de suma importância, um deles e o inventário físico, no qual a sua finalidade é analisar e comparar os dados já coletados com o sistema existente. Sendo de grande impacto na contabilidade da empresa, é necessário que o estoque tenha uma boa gestão de inventário. Mesmo demonstrando praticidade, o processo de conferência de inventários acaba sendo um grande desafio, pois dependerá de quais produtos serão analisados. O processo de auditoria em estoques reúne processos relacionados a dificuldades como grandes perdas em relação ao comercio e prazos mal estipulados.

\section{METODOLOGIA}

O presente estudobuscou detectar gargalos no processo de inventário de uma empresa de materiais de construção localizada na Zona da Mata de Minas Gerais. Considerada uma empresa de médio porte, tendo uma rede de distribuição de 14 pontos comerciais e 3 Centros de Distribuições (CD). A aplicação dessa pesquisa busca como resultado aumentar a 
acuracidade no estoque e propor um novo processo de operação. Os conceitos para todo o fundamento teórico foram pesquisas em artigos disponíveis no Google Acadêmico. Através dos conceitos foi possível a aplicação correta em ambiente prático, buscando apresentar informações de ferramentas de controle, métodos e controles da gestão de estoque e de inventário.

O desenvolvimento desse artigo fundamenta-se em simular o processo existente e realizar uma análise de possíveis gargalos encontrados, através da modelagem com software Arena que consiste em um ambiente gráfico integrado de simulação de processos, que contém recursos para modelagem como fluxogramas, análise de resultados e análise estatística,propondo que o novo processo seja mais enxuto. No presente trabalho foi usado a modelagem por meio de fluxogramas e análise de resultados. Além disso, será apontado quais ferramentas de gestão de inventariosão melhores práticas de gestão de estoque. Também utilizará a ferramenta Gráfico de Pareto, que tem comofunção o apontamentodas principais causas dos problemas, usando uma regra $20-80$, sendo que $20 \%$ das causas impactam em $80 \%$ dos meus problemas.

O estudo classifica-se em um trabalho prático comparativo, em 1 dos 3 CD's trazendo um ambiente de processo de inventario existente de operação desde o pedido de compras até a gestão de inventario. Inicialmente, foi realizado uma modelagem de processo AS IS: nela foi realizada a simulação do processo e análise crítica sobre a operação tendo como objetivo a detecção de gargalos atuais ou também chamados de "pontos de dor", Além de uma segunda modelagem TO BEcom o processo enxuto proposto.

Para a coleta de dados, realizou-se entrevistas com 3 funcionários chaves de o processo: o inventariante, com a função realizar o inventario; comprador, com função de negociação ecompra dos produtos e o auxiliar de recebimento, responsável pelo recebimento e conferência dos produtos que dão entrada na empresa. Foram extraídas informações do relatório denominado como relatório analítico de inventario, produzido pelo sistema de controle de estoque da empresa.Nesse relatório pode-se encontrar dados de todos os seguimentos: ranking de rentabilidade,quantidade de venda, demandas dos produtos, índice de acuracidade por SKU, pedidos de compras, abastecimento das lojas dentre outras informações.

O processo se inicia naextraçãode uma planilha composta estrategicamente e organizada na ordem decrescente com o índice de rentabilidade dentre com os SKU'S existentes na maleta de códigos de toda empresa. Com essa classificação é possível detectar qual produto tem o maior lucro dentre a empresa. 
Sendo catalogado o “top 10” dos SKU’s mais rentáveis, são dispostos para visualização do relatório "Ranking de rentabilidade", e o seguinte passo foi a aplicaçãoda ferramenta gráfico de Pareto, que é um composto gráfico que tem característica de gráfico de barras com a ordenação das frequências em ordem decrescente, que possibilita localizar e identificar a importância dos itens de analise em um englobado total.

Nas entrevistas foram coletadas informações da operação e gestão do código em análise, desde a gestão de compra até a gestão de inventário. Foi realizado a primeira modelagem AS IS no SKU em estudo, assim avaliando todo seu processo buscando um melhor processo proposto. Houve a construção do cálculo da acuracidade, assim utilizando dados disponíveis no sistema de relatório da empresa. Além disso, houve a construção dedois ambientes: o primeiro, onde se descreve a"acuracidade atual" e após processo modelado e TO BE construído, foi calculado a“acuracidade modificada”. Assim, podendo comparar os dois cenários.Utilizando as ferramentas estudadas e conceituadas no trabalho realizado, foi possível a implantação de outras ferramentas que não estão sendo aplicadas no processo existente.

\section{RESULTADOS E DISCUSSÕES}

No sistema de relatórios da empresa,foi extraídauma base de dados que apresenta os 10 SKU's mais rentáveis para empresa no primeiro semestre de 2020. Com esse relatório foi possível analisar quais SKU's são mais vantajosos visando lucratividade.

A Figura 1 apresenta o ranking dos produtos mais rentáveis em ordem decrescente e aponta o SKU 1890 - VARA FERRO 3/8 - 10 MM que obteve destaque e demandará atenção deste estudo.

Figura 1: Ranking dos produtos mais rentáveis.

\begin{tabular}{|c|c|c|c|c|c|c|c|c|}
\hline \multicolumn{9}{|c|}{ Ranking de Rentabilidade - Analítico por Produto } \\
\hline & SKU & Produto & Cus & o da Venda & & lor da venda & & Lucro \\
\hline 1 & $1-1890$ & VARA FERRO $3 / 8$ - $10 \mathrm{MM}$ & $\mathrm{R} \$$ & $788.478,10$ & $\mathrm{R} \$$ & $1.095 .855,89$ & $\mathrm{R} \$$ & $307.377,79$ \\
\hline 2 & $2-1889$ & VARA FERRO 5/16 - 8MM & $\mathrm{R} \$$ & $413.238,12$ & $\mathrm{R} \$$ & $623.404,57$ & $\mathrm{R} \$$ & $210.166,45$ \\
\hline 3 & $3-20644$ & CIMENTO CPIII - 40 RS 50KGS & $\mathrm{R} \$$ & $529.531,83$ & $\mathrm{R} \$$ & $725.853,28$ & $\mathrm{R} \$$ & $196.321,45$ \\
\hline 4 & $4-22124$ & VARA FERRO $5.0-5 \mathrm{MM}$ & $\mathrm{R} \$$ & $384.996,39$ & $\mathrm{RS}$ & $558.917,63$ & $\mathrm{R} \$$ & $173.921,24$ \\
\hline 5 & $5-1414$ & ARGAMASSA INTERNA 20KGS - ACI & $\mathrm{R} \$$ & $263.317,28$ & $\mathrm{R} \$$ & $398.390,60$ & $\mathrm{R} \$$ & $135.073,32$ \\
\hline 6 & $6-10101$ & ARGAMASSA FLEXÍVEL CINZA - ACIII & $\mathrm{R} \$$ & $296.207,63$ & $\mathrm{R} \$$ & $430.610,40$ & $\mathrm{R} \$$ & $134.402,77$ \\
\hline 7 & $7-44207$ & VARA FERRO $1 / 4-6,3 \mathrm{MM}$ & $\mathrm{R} \$$ & $366.514,45$ & $\mathrm{R} \$$ & $489.411,77$ & $\mathrm{RS}$ & $122.897,32$ \\
\hline 8 & $8-13613$ & ARGAMASSA PORCEL. INT. CINZA 20KGS & $\mathrm{R} \$$ & $198.042,40$ & $\mathrm{R} \$$ & $285.798,56$ & $\mathrm{RS}$ & $87.756,16$ \\
\hline 9 & $9-1891$ & VARA FERRO $1 / 2-12,5 \mathrm{MM}$ & $\mathrm{RS}$ & $255.863,74$ & $\mathrm{RS}$ & $341.426,38$ & $\mathrm{R} \$$ & $85.562,64$ \\
\hline 10 & $10-44071$ & PORCEL. 60×60 PAVIMENTE GRAY RET & $\mathrm{R} \$$ & $171.000,12$ & $\mathrm{R} \$$ & $245.675,97$ & $\mathrm{R} \$$ & $74.675,85$ \\
\hline
\end{tabular}

Fonte: Planilha extraída do sistema de relatório da empresa (2020). 
Para elaboração do Gráfico de Pareto conforme figura 2, foramcalculadas outras duas colunas, o lucro acumulado e o percentual dos SKU's sobre o total acumulado. Com sua aplicação, foi demonstrado que o produto 1890 - VARA FERRO3/8-10MM representa $20,11 \%$ entre os 10 SKU's mais rentáveis do primeiro semestre de 2020.

Figura 2: Quadro de dados para construção do Gráfico de Pareto:

\begin{tabular}{|c|c|c|c|c|c|c|c|c|c|c|}
\hline \multicolumn{11}{|c|}{ Ranking de Rentabilidade - Analítico por Produto } \\
\hline & SKU & Produto & Cus & o da Venda & & lor da venda & & Lucro & Acumulado & $\%$ Acumulado \\
\hline 1 & 1890 & VARA FERRO $3 / 8-10 \mathrm{MM}$ & $\mathrm{RS}$ & $788.478,10$ & $\mathrm{R} \$$ & $1.095 .855,89$ & $\mathrm{RS}$ & $307.377,79$ & R\$ $\quad 307.377,79$ & $20,11 \%$ \\
\hline 3 & 1889 & VARA FERRO $5 / 16-8 \mathrm{MM}$ & $\mathrm{R} \$$ & $413.238,12$ & $\mathrm{RS}$ & $623.404,57$ & $\mathrm{R} \$$ & $210.166,45$ & $517.544,24$ & $33,87 \%$ \\
\hline 2 & 20644 & CIMENTO CPIII - 40 RS 50KGS & $\mathrm{RS}$ & $529.531,83$ & RȘ & $725.853,28$ & $\mathrm{RS}$ & $196.321,45$ & $713.865,69$ & $46,71 \%$ \\
\hline 4 & 22124 & VARA FERRO 5.0 - $5 \mathrm{MM}$ & $\mathrm{RS}$ & $384.996,39$ & $\mathrm{RS}$ & $558.917,63$ & $\mathrm{RS}$ & $173.921,24$ & $\mathrm{R} \$ \quad 887.786,93$ & $58,10 \%$ \\
\hline 7 & 1414 & ARGAMASSA INTERNA 20KGS - ACI & $\mathrm{R} \$$ & $263.317,28$ & RȘ & $398.390,60$ & $\mathrm{RS}$ & $135.073,32$ & $\mathrm{R} \$ 1.022 .860,25$ & $66,93 \%$ \\
\hline 6 & 10101 & ARGAMASSA FLEXÍVEL CINZA - ACIII & $\mathrm{RS}$ & $296.207,63$ & $\mathrm{RS}$ & $430.610,40$ & $\mathrm{R} \$$ & $134.402,77$ & $\mathrm{R} \$ 1.157 .263,02$ & $75,73 \%$ \\
\hline 5 & 44207 & VARA FERRO $1 / 4-6,3 \mathrm{MM}$ & $\mathrm{R} \$$ & $366.514,45$ & $\mathrm{RS}$ & $489.411,77$ & $\mathrm{RS}$ & $122.897,32$ & $\mathrm{R} \$ 1.280 .160,34$ & $83,77 \%$ \\
\hline 9 & 13613 & ARGAMASSA PORCEL. INT. CINZA 20KGS & $\mathrm{R} \$$ & $198.042,40$ & $\mathrm{RS}$ & $285.798,56$ & $\mathrm{RS}$ & $87.756,16$ & $\mathrm{R} \$ 1.367 .916,50$ & $89,51 \%$ \\
\hline 8 & 1891 & VARA FERRO $1 / 2-12,5 \mathrm{MM}$ & $\mathrm{R} \$$ & $255.863,74$ & $\mathrm{RS}$ & $341.426,38$ & $\mathrm{RS}$ & $85.562,64$ & $\mathrm{R} \$ 1.453 .479,14$ & $95,11 \%$ \\
\hline 10 & 44071 & PORCEL. 60X60 PAVIMENTE GRAY RET & $\mathrm{R} \$$ & $171.000,12$ & $\mathrm{RS}$ & $245.675,97$ & $\mathrm{R} \$$ & $74.675,85$ & $\mathrm{R} \$ 1.528 .154,99$ & $100,00 \%$ \\
\hline
\end{tabular}

Fonte: Próprio autor (2020)

A Figura 3 correlacionada com a tabela acima, apresenta o Gráfico de Pareto dos produtos mais rentáveis e novamente expressa graficamente a representatividade de $20,11 \%$ no SKU 1890 - VARA FERRO 3/8 - 10MM.

Figura 3: Gráfico de Pareto dos produtos mais rentáveis

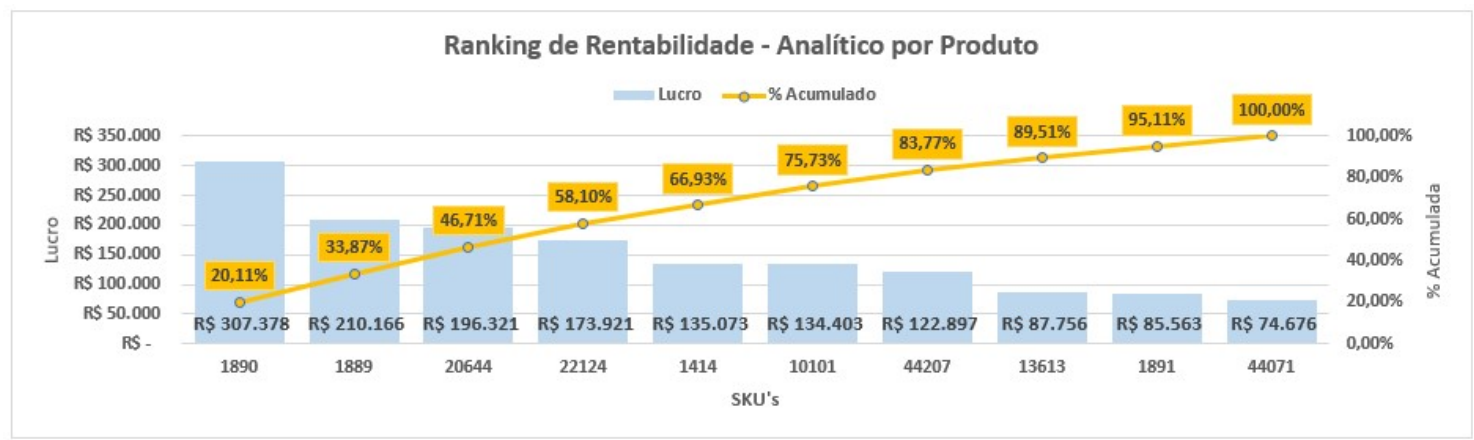

Fonte: Próprio autor (2020)

A partir da verificação no Gráfico de Pareto, foi selecionado o SKU 1890 - VARA FERRO 3/8 - 10MM para mapear o seu processo AS IS, desde o recebimento do produto na empresa estudada até a sua venda, passando pelo seu processo de inventário, cálculo e análise de sua acuracidade nos meses de junho, julho e agosto de 2020, até o realizado no mêsde setembro de 2020 com a implantação do processo TO BE, quebusca a implantação da nova modelagem de inventário no código em estudo. 
Com o código já selecionado, foram realizadas entrevistas com 2 funcionários que atuam há 9 anos na empresa. Eles possuem o cargo de Assistente de Almoxarifado, possuindo apenas o grau de escolaridade ensino médio incompleto. Foi entrevistado também 1 funcionário da área de compras,como cargo de Assistente Administrativo I, atuando na empresa há 4 anos, possuindo o grau de escolaridade de nível superior completo.

Os 3 funcionários foram escolhidos por seremusuários chaves do processo de inventário e compras do Centro de Distribuição (CD), assim tendo o total conhecimento do processo em estudo. Foi construída uma tabela com pontos que serão analisados no estudo, com perguntas estratégicas para absorver do funcionário o total entendimento do processo.

Figura 4: Quadro utilizado na entrevista perguntas X Funcionalidade

\begin{tabular}{|c|c|c|}
\hline Perguntas & Funcionalidade & Ficou claro? \\
\hline $\begin{array}{c}\text { Quantas etapas possuem o } \\
\text { processo? }\end{array}$ & $\begin{array}{c}\text { Entender a dimensão } \\
\text { do processo. }\end{array}$ & Sim \\
\hline $\begin{array}{c}\text { Explique as etapas do } \\
\text { processo. }\end{array}$ & Definir as etapas. & Sim \\
\hline O processo possui gargalo? & Detectar falhas. & Sim \\
\hline Se sim, cite qual é? & $\begin{array}{c}\text { Oportunidade de } \\
\text { estudo. }\end{array}$ & Sim \\
\hline
\end{tabular}

Fonte: Próprio autor (2020)

\subsection{Fluxo do processo ASIS}

O processo existente na empresa para o SKU 1890 é constituído por 5 etapas e ocorre deste que o $\mathrm{CD}$ em estudo foi construído. Observe-se que analisando as descrições abaixo de cada etapa e o fluxo de processo (Figura 5), o inventário ocorre como uma medida corretiva quando uma anomalia é encontrada, já na etapa de armazenamento dos produtos para o cliente. Abaixoforam enfatizadas as ações ocorridas dentro de cada etapa do processo:

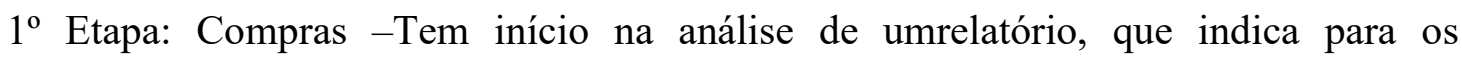
compradores se o produto está em falta ou sua provável falta. Desta forma, coloca-se uma porcentagem de demanda de compra, emitindo, assim, o pedido de compras para envio aos fornecedores.

$2^{\text {a }}$ Etapa: Recebimento de mercadoria-Ocorre o recebimento, conferencia e contabilização da entrada da nota fiscal do fornecedor.

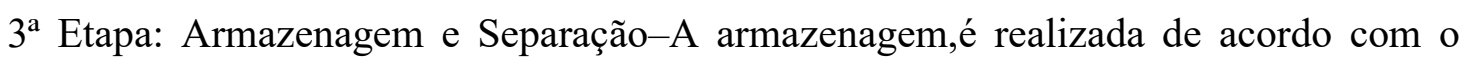
tamanho e a bitola,que são organizados conforme demanda de saída. Nessa parte do 
processoocorre a separação para o cliente. Caso na separação seja observado alguma anomalia, é realizado em caráter de correção o inventário do SKU em análise.

$4^{\text {a }}$ Etapa: Faturamento - São as notas fiscais do produto que são emitidas para o envio do comprador.

$5^{\text {a }}$ Etapa: Entrega - Entrega para o cliente.

Para analisar o comportamento de todo o processo do SKU dentro do CD, foi construída uma modelagem de processo no software Arenade maneira a demonstrar a dinâmica dos processos do SKU 1890 - VARA DE FERRO 3/8 - 10MM, conforme Figura5.

Figura 5: Fluxo do processo do SKU 1890 - VARA FERRO 3/810MM.

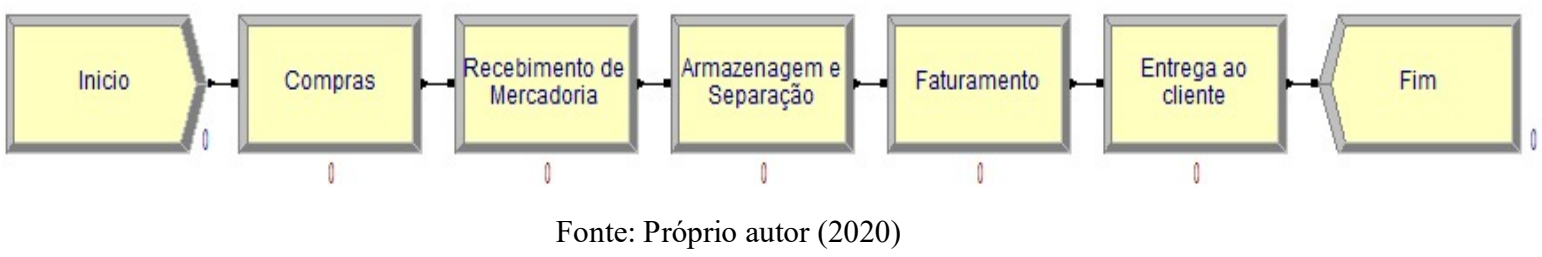

Dentre as 5 etapas do processo, a que apresentou "ponto de dor" foi na etapa de armazenamento e separação do produto. Observou-se que o processo de inventário na modelagem " $A S I S$ " somente ocorre no momento da separação dos pedidos para os clientes, em casos de detectar alguma anomalia. Sendo assim, tendo a característica de medida corretiva no estoque.Com essa execução de inventário foi encontrada uma baixa acuracidade de estoque no SKU 1890 em análise.

A Figura 5 apresenta a acuracidade ainda na modelagem AS IS do SKU 1890 VARA DE FERRO 3/8 - 10MM, realizada nos meses de junho, julho e agosto de 2020:

Figura 6: Quadro de acuracidade processos $A S$ ISdo SKU 1890 - VARA FERRO 3/8 - 10MM

\begin{tabular}{|c|c|l|c|c|c|}
\hline \multicolumn{6}{|c|}{ Acuracidade - AS IS } \\
\hline SKU & Mês & \multicolumn{1}{|c|}{ Produto } & Estoque Físico & Estoque Virtual & Acuracidade \\
\hline $1-1890$ & jun/20 & $\begin{array}{l}\text { VARA FERRO 3/8 } \\
10 \text { MM }\end{array}$ & 875 & 1117 & $78,33 \%$ \\
\hline $1-1890$ & $j u l / 20$ & $\begin{array}{l}\text { VARA FERRO 3/8 } \\
10 \text { MM }\end{array}$ & 225 & 285 & $78,95 \%$ \\
\hline $1-1890$ & ago/20 & $\begin{array}{l}\text { VARA FERRO 3/8 } \\
10 \text { MM }\end{array}$ & 2300 & 2854 & $80,59 \%$ \\
\hline
\end{tabular}

Fonte: Planilha de controle (2020). 
O quadroda figura 6 foi construído a partir dos dados coletados pelos inventariantes nos meses de junho, julho e agosto de 2020, onde foram demostrados resultadosinsatisfatórios com a abordagem de controleASIS.

Figura 7: Demonstração gráfica da acuracidade ASIS

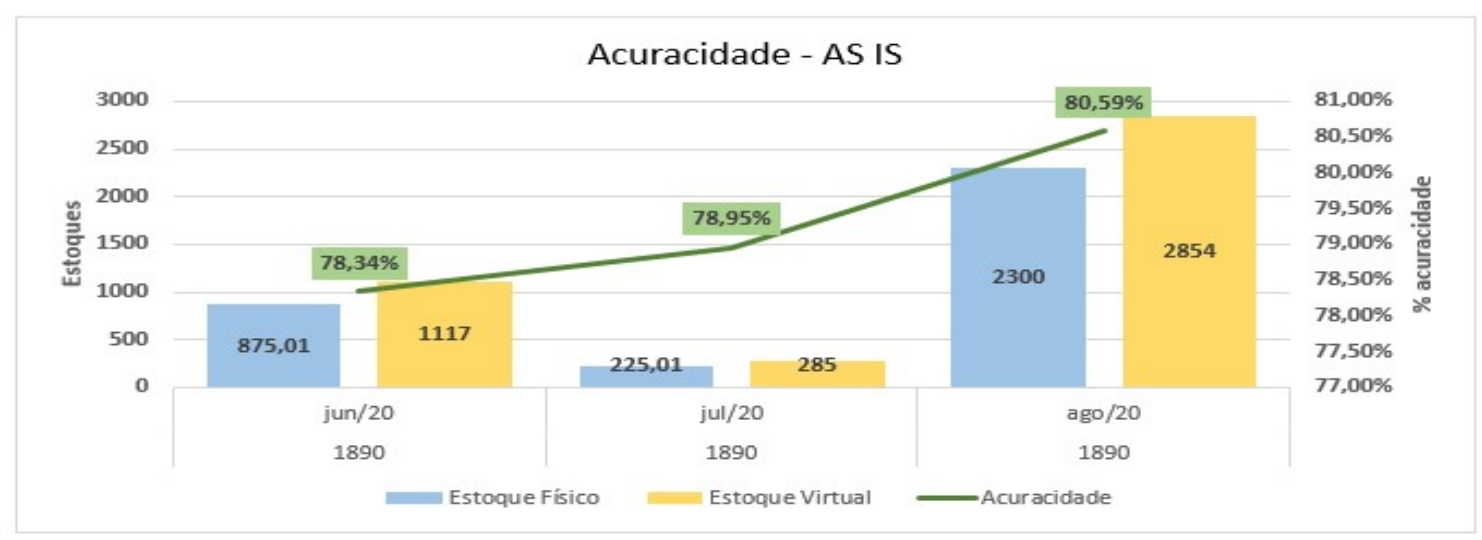

Fonte: Próprio autor (2020)

Conforme defendido por Gasnier(2002), acuracidadeé um indicador gerencial, sendo expressa pela proporção de informações corretas na comparação entre o estoque físico e o virtual. Na busca pelo aumento da acuracidade é de grande importância a análise do desvio relativo de acordo com o tipo de inventário ocorrido no estoque.

Ainda segundo Gasnier (2002), é possível representar os possíveis resultados de acuracidade a ser encontrado a partir de cada metodologia de inventário realizado. Essa representatividade é mostrada na Figura 8, que trás as tecnologias que podem ser empregadas no processo de inventário.

Figura 8: Gráfico de tecnologias empregadas defendidas por Gasnier (2002).

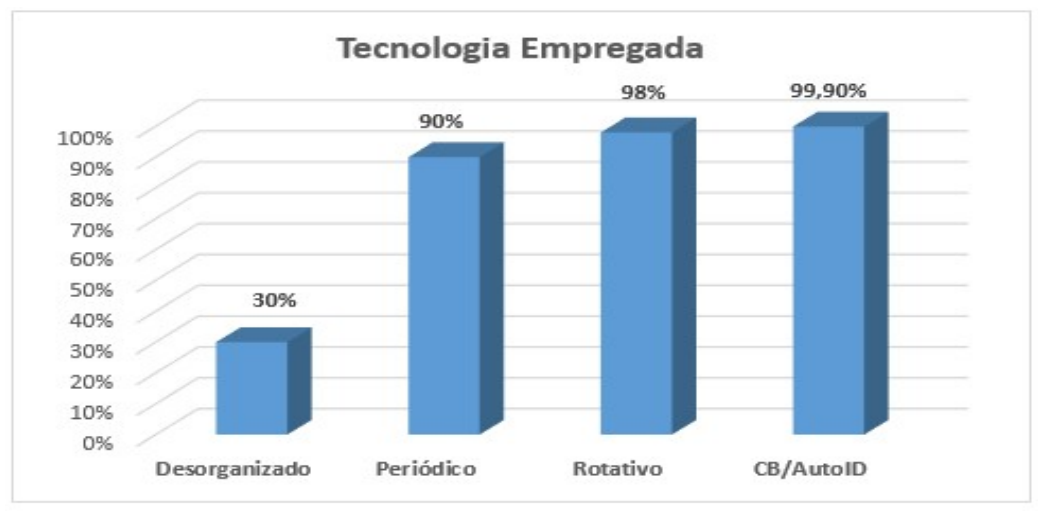

Fonte: Gasnier(2002) adaptado pelo autor. 
$\mathrm{Na}$ empresa em estudo no processo $A S I S$, é realizado o inventário periódico que tem a característica de não ter como premissa um período pré-determinado, possuindoa aplicação de acordo com o processo e mantendo a política implantada na empresa. Destaca-se que a ação de contagem é totalmente manual e sem uso de tecnologias.

O estoque $A S I S$ do SKU trabalhado é o periódico, que consiste em um índice de acuracidademínimo aceitável de 90\%. Em análise dos meses expostos nasFigura 6e Figura 7, o índice está menor que o aceitável. Sendo assim, foi proposta uma nova modelagem TO BE com implantação do inventário rotativo, afim de elevar o índice de acuracidade do SKU estudado.

\subsection{Proposta de ProcessoTO BE}

Após análise da modelagem $A S I S$ (Figura 5), foi proposto nova modelagem TO BE no processo com a busca para aumentar a exatidão do estoque, com o inventário rotativo, assim elevando o índiceda acuracidade do SKUem estudo.

No novo processo proposto e com base nos dados analisados, foram propostas as seguintes melhorias com os respectivos objetivos:

Ação 1: Inventários semanais no código em estudo.Consiste na ação de contagem do SKU 1890, onde é realizada a conferência dos feixos que são compostos por 5 unidades de VARA FERRO 3/8-10MM. Após a contabilização, são lançados os dados em uma planilha de controle que possui fórmula para o cálculo da acuracidade.

Objetivo da Ação 1: Manter o estoquede produtos VARA FERRO 3/8-10MM físico igual ao virtual, assim obtendo a confiabilidade dos estoques e elevando a índice de acuracidade.

Com implantação dos inventários semanais, foram propostas alterações no fluxo do processo do SKU em estudo. Houve o desmembramento da etapa armazenagem e separação, que no fluxo AS IS ocorria de forma conjunta. Foiacrescentado o processo de inventário após a execução da etapa armazenagem e antes da etapa separação. Tal processo é demostrado na Figura 8. Segue abaixo a descrição das etapas propostas no processo TO BE.

$1^{\circ}$ Etapa: Compras - Tem início na análise num relatório, que indica para os compradores se o produto está em falta ou sua provável falta. Desta forma, eles colocam uma porcentagem de demanda de compra, e então é emitido e enviado o pedido de compra ao fornecedor. 


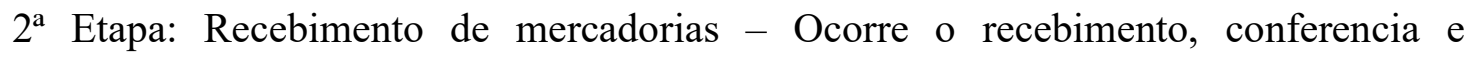
contabilização da entrada da nota fiscal do fornecedor.

$3^{\text {a }}$ Etapa: Armazenagem: É realizada de acordo com o tamanho e a bitola, eles são organizados conforme demanda de saída.

4 a Etapa: Inventário: Contagem semanal do SKU com o lançamento dos dados na planilha de controle.

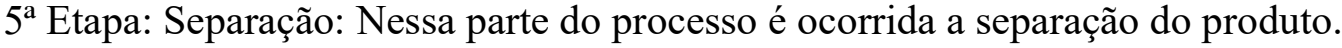

$6^{\mathrm{a}}$ Etapa: Faturamento - São as notas fiscais do produto que são emitidas para o envio do cliente.

Figura 9: Fluxo TO BE do processo do SKU 1890 - VARA FERRO 3/8 - 10MM.

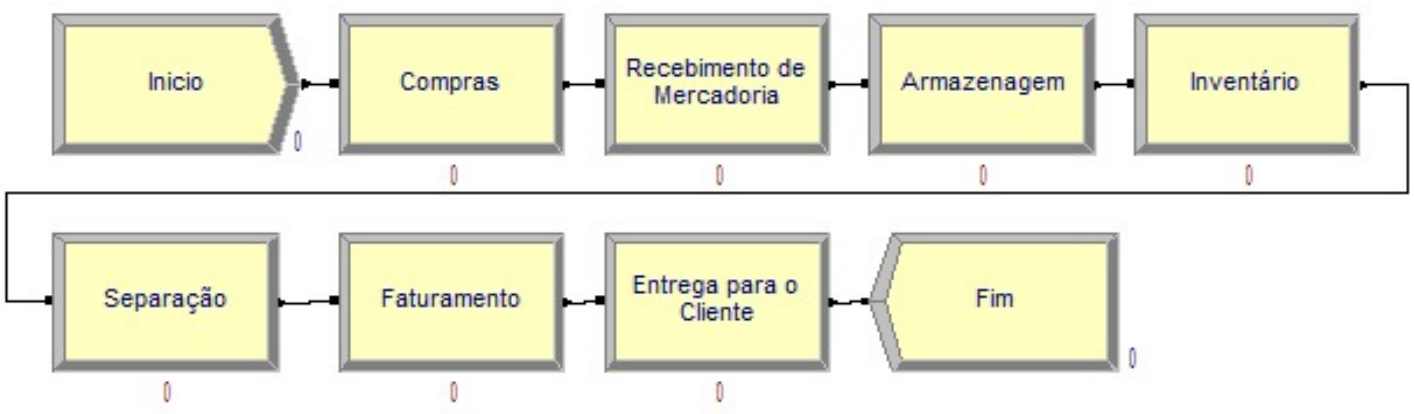

Fonte: Próprio autor (2020).

Com o processo proposto e ação implantada, obteve-se a acuracidade do SKU trabalhado conforme Figura10,sendo apresentada uma evolução gradual no mês de setembro de 2020, saindo de 96\% na primeira semana e alcançando o nível de 98\% de acuracidade na quarta semana (a última acuracidade medida no mês de agosto de 2020 antes do TO BE implantado foi de $80,59 \%$ ).

Figura 10: Tabela de controle de inventário TO BE do SKU 1890 - VARA FERRO 3/8 - 10MM:

\begin{tabular}{|c|c|l|c|c|r|}
\hline \multicolumn{7}{|c|}{ Acuracidade - TO BE } \\
\hline SKU & Mês & \multicolumn{1}{|c|}{ Produto } & Estoque Físico & Estoque Virtual & Acuracidade \\
\hline $1-1890$ & SEMANA 1 & $\begin{array}{l}\text { VARA FERRO 3/8 } \\
10 \text { MM }\end{array}$ & 1550 & 1615 & $96 \%$ \\
\hline $1-1890$ & SEMANA 2 & $\begin{array}{l}\text { VARA FERRO 3/8 } \\
10 \text { MM }\end{array}$ & 1000 & 1030 & $97 \%$ \\
\hline $1-1890$ & SEMANA 3 & $\begin{array}{l}\text { VARA FERRO 3/8 - } \\
10 \text { MM }\end{array}$ & 600 & 618 & $97 \%$ \\
\hline $1-1890$ & SEMANA 4 & $\begin{array}{l}\text { VARA FERRO 3/8 - } \\
\text { 10MM }\end{array}$ & 345 & 352 & $98 \%$ \\
\hline
\end{tabular}

Fonte: Planilha de controle(2020) 
O gráfico da figura 11 foi construído a partir dos dados coletados pelos inventariantes no mês setembro, onde foi aplicado a ferramenta de inventário semanal. Como demonstrado abaixo, o índice de acuracidade entre as semanas teve um gradual crescimento.

Figura 11: Demonstração gráfica da acuracidade TO BE

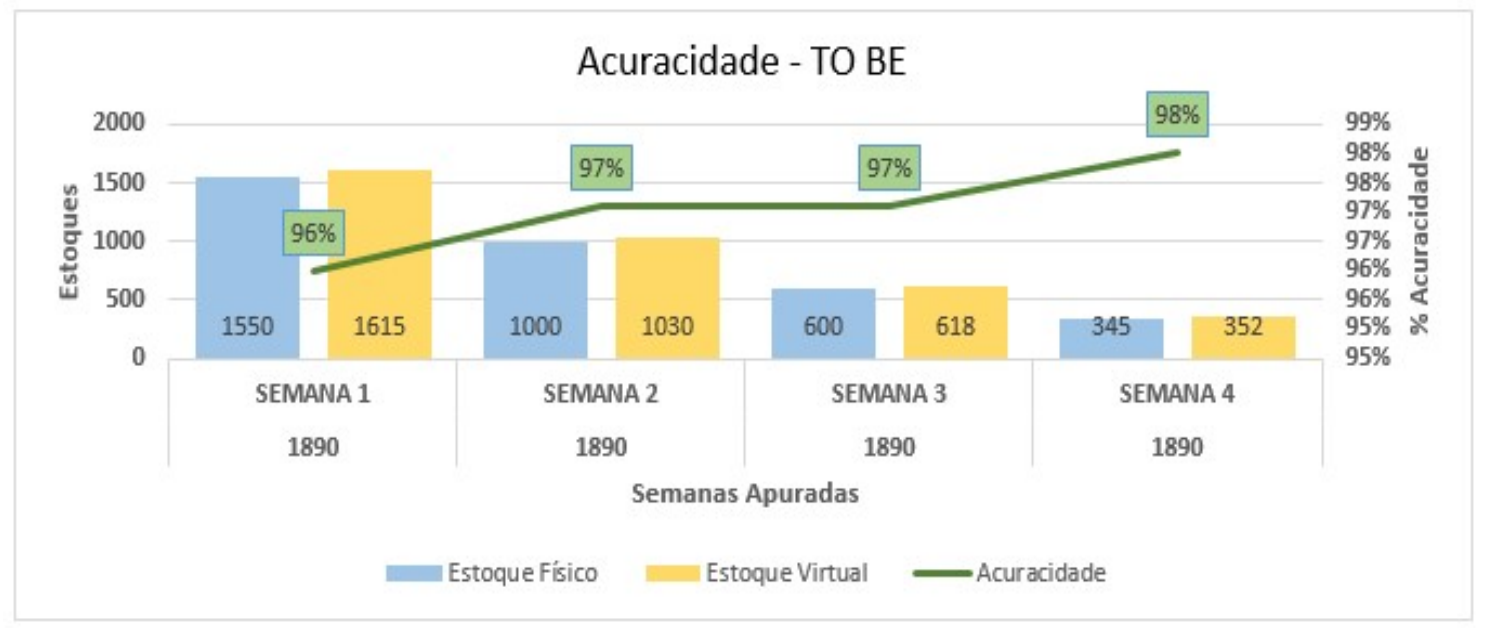

Fonte: Próprio autor (2020)

Após a análise da acuracidade nas quatro semanas de setembrode 2020 (Figura 11), foi constatado que houve uma divergência de $2 \%$ no resultado, impossibilitando alcançar a acuracidade de $100 \%$. Esta divergência foi verificada e segue a justificativa: o erro foi apresentado naseparação da nota fiscal do material VARA FERRO 3/8-10MM, onde nesta etapa de separação e entrega os feixos foram trocados pelo SKU 1889 - VARA FERRO 5/16 - 8MM.O Quadro 12 apresenta detalhes que justificam a divergência de 2\% encontrada no inventário da $4^{\mathrm{a}}$ semana do mês de setembro de 2020 :

Quadro 12: Identificação da Atividade ou Defeito.

\begin{tabular}{|c|c|c|c|c|c|}
\hline \multicolumn{6}{|c|}{ Identificação da Atividade ou Defeito } \\
\hline $\mathrm{O}$ que? & Quem? & Onde? & Quando? & Como? & Por que? \\
\hline $\begin{array}{l}\text { Separação de SKU } \\
\text { para entrega ao } \\
\text { cliente de forma } \\
\text { incorreta. }\end{array}$ & $\begin{array}{l}\text { Auxiliares } \\
\text { de } \\
\text { Serralheria }\end{array}$ & $\begin{array}{l}\text { Etapa } \\
\text { Separação } \\
\text { de produtos }\end{array}$ & $\begin{array}{l}\text { Determinação } \\
\text { atraves de } \\
\text { cronograma. }\end{array}$ & $\begin{array}{l}\text { Ao separar os } \\
\text { produtos para } \\
\text { entrega, ocorreu } \\
\text { divergencia de } \\
\text { produtos entregues. }\end{array}$ & $\begin{array}{l}\text { Os SKU são } \\
\text { semelhantes, } \\
\text { tendo como } \\
\text { diferença a } \\
\text { bitola. }\end{array}$ \\
\hline
\end{tabular}

Fonte: Próprio autor(2020)

Com a divergência de $2 \%$ na acuracidade do SKU, esta variação pode ocorrer pelo fato de que na empresa em questão também se comercializa em sua maleta de produtos outros 
tipos de vara de ferro. Toda armazenagem é feita no mesmo setor, havendo diferenças somente na separação, que é realizada por tamanho e bitola.

Através da aplicação do estudo, foi possível obter um aumento no índice de confiabilidade no estoque do SKU em questão,com a implantação de uma metodologia totalmente sem gastos tecnológicos utilizando apenas uma nova modelagem no processo de inventário.

\section{CONCLUSÃO}

A gestão de inventário atrelada diretamente a gestão de estoque se torna extremamente importante, pois se há um controle eficaz de inventário, os estoques físico e virtual se mantêm corretos e consequentemente, não ocasionará em perda de vendas e haverá diminuição de problemas em outros processos que a empresa desenvolve.

O presente estudo partir de uma modelagem AI IS e possibilitou a elaboração de uma nova modelagem TO BE.Analisando os dados da modelagem AS IS, foi possível identificar que as ações realizadas na gestão de inventário da empresa eram mínimas, corretivas e poucos assertivas. Desta forma a nova modelagem TO BE aplicada visa controlar o estoque e aumentar a acuracidade dos estoques e trazerconfiabilidade das informações disponibilizadas pelo sistema da empresa e pelo estoque físico.

Manter o índice alto de acuracidadeatravés de inventários assertivos e rotativo, é fundamental para uma empresa que almeja elevar seu nível de competitividade no mercado. Com isto, a proposta é aumentar o nível de acuracidade do SKU mais rentável para empresa.Com a implementação de inventários semanais, o resultado encontrado no SKU trabalhado apresentou uma grande evolução nas semanas de setembro de 2020 sendo usado um método manual sem investimento de tecnologia, saindo de $96 \%$ na primeira semana e chegando ao nível de $98 \%$ de acuracidade na quarta semana. Sendo que a última acuracidade medida no $A S I S$ no mês de agosto de 2020 antes do TO BE implantado foram de 80,59\%.

Após a aplicação da nova modelagem de processo da gestão de inventário no CD da empresa, foi possível observar o quanto as ferramentas aplicadas foram um diferencial em relação ao controle do estoque existente, afim da diminuição de perda de material, atrasos e vencimento de seus produtos em comparação com a antiga modelagem.

Para estudos futuros pode se aplicar a mesma metodologia deste estudo dentre os outros códigos que também são de rentabilidade significativa para e empresa. Assim, cada vez 
obtendo um estoque confiável através da contagem rotativa e sem investimento em tecnologia.

\section{REFERÊNCIAS BIBLIOGRÁFICAS}

BARBOSA, E. S.; Filho, H. P. C. Gestão de Estoque nas Pequenas Empresas: Um Estudo de caso no Mercadinho e Hortifruti XY. Disponível em: $<$ https://idonline.emnuvens.com.br/id/article/view/2068>. Acesso em 10 de Março de 2020.

CAMARGO, T. P. Gestão de estoques em órgão público: o caso do Hospital Universitário Polydoro Hernani de São Thiago. Disponível em: $<$ https://repositorio.ufsc.br/xmlui/handle/123456789/176937>. Acesso em 12 de Março de 2020.

GASNIER, D.G. A dinâmica dos estoques: guia prático para planejamento, gestão de materiais e logística. São Paulo: IMAM, 2002.

RIGOlETO, A. A.; Pereira, E. M.; Duran, J. E. Gestão de estoque como ferramenta estratégica na redução de custos. Disponível em: $<$ http://revista.facfama.edu.br/index.php/ROS/article/view/308>. Acesso em 12 de Março de 2020.

RIZZOTO, F. H. Otimização da gestão de inventários na rede varejista Gandhi Confecções Me. Disponível em <https://core.ac.uk/download/pdf/78548034.pdf. > Acesso em 10 de Março de 2020. 